\title{
PRIMERAS OBSERVACIONES PARA UNA DATACIÓN PALEOGRÁFICA DE LA ESCRITURA IBÉRICA
}

\author{
POR
}

\author{
JESÚS RODRÍGUEZ RAMOS
}

\section{RESUMEN}

Ésta es la primera vez en que se estudia un método para la datación paleográfica de las inscripciones escritas en el semisilabario ibérico levantino. Se basa en los doce signos más relevantes y, a pesar de que eventuales análisis posteriores aportarán una mayor precisión, de hecho el sistema expuesto ya permite identificar seis fases cronológicas en la evolución de la escritura levantina. Asimismo se ejemplifica el método a través del estudio de diez de las inscripciones más largas y significativas y se indica su relación evolutiva con la escritura celtibérica.

\section{SUMMARY}

This is the first approach to a method for paleographically dating the inscriptions written in the Levantine Iberian semisillabary. It is based on the twelve more relevant sings and even though further analyses will eventually afford greater accuracy, the system such as it is being set forth now allows for identification of six chronological phases in the evolution of the Levantine Iberian writing. It is also exemplified through the study of the longest ten pertinent inscriptions that denotes the model relation with its evolution in the Celtiberian writing.

Un procedimiento bien conocido en el ámbito de la epigrafía para precisar la datación de un monumento consiste en el reconocimiento de las dataciones respectivas de las diversas formas que un mismo signo puede presentar, así como de las asociaciones de las diversas formas de signos diferentes (es decir, la cronología de uso de un signario). Desgraciadamente, hasta el momento no se ha realizado un estudio tal para la epigrafía ibérica. Sólo pueden mencionarse algunos análisis paleográficos circunscritos a las leyendas monetales (principalmente debidos a Villaronga 1967, 1978 y 1979) y algunas consideraciones realizadas por Maluquer de Motes en su Epigrafía Prelatina, en 1968, ya desde un punto de vista más general y arqueológico ${ }^{1}$.

1 Maluquer indicaba los signos que identificaba sobre cada tipo de material (cerámica de Liria, leyenda monetal, campaniense $\mathrm{A}$, etc.). No obstante, el escaso número de inscripciones disponibles, el mal conocimiento en la época de
Es cierto que un estudio de este tipo topa, aún hoy, con algunas dificultades evidentes. Además de la manifiesta deformación que produce el que sólo hayan sobrevivido las inscripciones sobre soportes duros, hay que recordar también que hay zonas mucho mejor conocidas arqueológicamente que otras, que hay fases cronológicamente más difíciles de concretar por presentar materiales de importación poco conocidos o de datación imprecisa, y que numéricamente están sobrevaloradas las inscripciones correspondientes a fases de destrucciones generalizadas ${ }^{2}$. De esta manera, el siglo Iv sólo puede estudiarse a grandes rasgos; es muy escasa la documentación de la primera mitad del s. III, y poco claros los detalles dentro de la primera mitad del s. II.

Es, consecuentemente, la intención del presente trabajo el hacer un análisis de los signos más relevantes, indicándose las fases de cronología relativa cuyas agrupaciones denotan, así como plantear a qué dataciones absolutas parecen corresponder. $\mathrm{Si}$ bien los resultados son, en su detalle, todavía provisionales y resumidos, en su conjunto componen una armazón sólida y coherente. Este análisis se fundamenta en unas setecientas inscripciones seleccionadas por su interés paleográfico y en sus dataciones. Ello ha permitido sacar unas primeras conclusiones que han sido ajustadas por criterios de copresencia de signos. Esto permite que cuando un signo denota una cronología determinada, si otro aparece con él puede deducirse que comparte al menos parte de su lapso cronológico. Este análisis asociativo parece confirmar en sus principales rasgos las conclusiones derivadas del cronológico, como veremos ejemplificado en el estudio del signario empleado por diez de

diversas producciones de barniz negro y el no pretender más que una exposición superficial, sin volver a analizar los resultados ni correlacionar signarios, representaron serias limitaciones. Ello, junto a una serie de erratas de edición que hacen difícil saber lo que exactamente quería decir Maluquer, han hecho que este estudio esté desaprovechado.

2 Especialmente en el caso de los 'plomos', cuyo material era reciclado borrando inscripciones previas para hacer nuevas. Pero éste dejaba de reciclarse cuando un poblado era destruido y el plomo quedaba entre las ruinas. 
los más importantes textos largos de la epigrafía ibérica levantina.

Esta estructuración es fundamentalmente válida para las zonas costeras, ya que en el interior, en aquellas zonas donde la escritura ibérica llega a inicios del s. II (verosímilmente por movimientos migratorios provocados a causa de la ocupación romana), se aprecian indicios de perduración de los signos. Ello es especialmente evidente en el signario celtibérico meridional (el propio de Luzaga), probable en la zona pirenaica, al menos para los inicios de la cecas del grupo oscense ${ }^{3}$, y posible en el caso de las inscripciones rupestres de la Cerdaña francesa. Grupo pirenaico que denota influencia del signario de la zona indiketa-sordona.

Evidentemente el análisis de las formas de los signos desde un punto de vista paleográfico permite una clasificación de los mismos más precisa que las tipologías meramente formales y la numeración utilizada es propia e independiente de la del 'corpus' de Untermann, cuya última versión puede encontrarse en $M L H$ III, 1.

Otra apreciación interesante es que existe una serie de variantes de signos que pueden presentarse en cualquier época, pese a que ya se hayan producido formas innovadas de los mismos. Componen lo que podríamos llamar el signario clásico. Tales son: $a-1{ }^{4}, l-1, \dot{m}-1, \dot{r}-1, t i-1$ y $t o-1$

\section{LA CRONOLOGÍA DE LOS SIGNOS RELEVANTES CONSIDERADOS DE UNO EN UNO}

Los signos más informativos en su diversidad morfológica son los siguientes: $a, o, l, \dot{m}, \dot{r}, s, b a$, $b e, k e, t e, t i$ y to. De todos ellos, el más importante por presentar más variedad y precisión diacrónica es $b e$, constituyéndose en un auténtico 'fósil director'.

Signo be: permite establecer cuatro fases claramente diferenciadas: arcaica (A), media (B), transicional (C) y moderna (D).

\section{Formas arcaicas: $(425-300)^{4}$}

be-1: aparece sobre la cerámica ática de Ullastret-33 C.2.33 (s. Iv). Dado que morfológicamente es la más arcaica y próxima a la meridional ${ }^{6}$ es plausible considerar que es previa a la segunda mitad del s. IV. $b e-1: i 425-350$ ?

be-4: un caso en Pontós-02 C.3.2 considerado de la primera mitad del IV. be-4: i400-350?

be-2: sobre diversas piezas áticas de Ullastret (C.2.17, 22, 23, 25 y 34) (s. Iv) y sobre una cerámica de barniz negro Lamboglia 40: Enserune-22 B.1.25 (325-225). Corresponde 'grosso modo' al s. IV. be-2: 400/350-300.

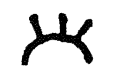

be-1

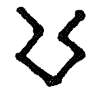

be -8

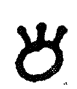

be-2

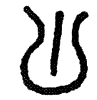

be $-9 a$

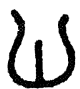

$b e-9 b$

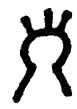

be-3

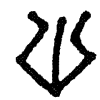

be-10a

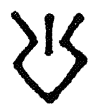

be- $10 b$

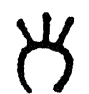

be-4

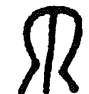

be-11a

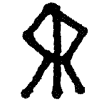

$b-11 b$

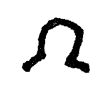

be -5

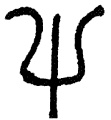

be-12

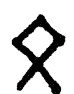

be-6

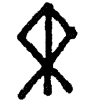

be-13

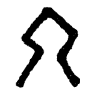

be-7

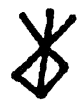

be-14

Fig. 1.-Clasificación de las formas de be.

${ }^{3}$ Identificado por Villaronga en la ceca sesars, si bien su datación post 141 al considerar que el literal bon corresponde al ideograma de denario no es segura.
${ }^{4}$ Por motivos tipográficos no se sigue la convención habitual de transcribir las lecturas de signos de semisilabarios ibéricos mediante letra negrilla, sustituyéndose por cursiva sin que ello implique, naturalmente, que se trate de textos greco-ibéricos. 
be-3: sobre un plomo de Ullastret-05 C.2.5 localizado en un estrato que presentaba cerámicas áticas. be-3: ¿s. Iv?

\section{Formas medias: (300-200)}

be-9: es habitual en la cerámica pintada de Liria (250-180), lapso cuya fase final debe estar marcada por $b e-11$; en una posible campaniense de Enserune- $46^{7}$ B.1.49 y en el plomo de Palamós C.4.1 (300-250). be-9: 300-200.

be-10: se localiza en cerámica pintada de Liria (250-180), en los plomos de Pech-Maho B.7.34-37 (250/225-200), pero también en la cista de PechMaho-01 B.7.1 (i300-250?) y en dos de los plomos de la tumba II de Orleyl F.9.5 y 7 (post 325). be-10: 300-200.

be-12: derivado cursivo lirimorfo de $b e-9$, que se halla en tres casos de la cerámica de Liria (250-180); sería previo al uso de be-11. be-12: ¿250-200?

\section{Formas transicionales: (210/200-180/150)}

be-11: se halla en dos cerámicas de Liria (250180), correspondiendo presumiblemente a la fase final del lapso. En el plomo de Tivissa-06 plausiblemente coetáneo a una fase de destrucción de época de Catón ${ }^{8}$ (ca. 195), presencia dudosa en una pieza de barniz negro de Enserune-178 B.1.182 y en diversas inscripciones rupestres de difícil lectura de Osseja, cuya existencia viene siendo relacionada

\footnotetext{
5 Para las dataciones he seguido una serie de convenciones que consisten básicamente en considerar que, por defecto, la escritura ibérica levantina cubre un período de 425 / 400-50 a.C., salvo algún caso concreto determinable. Ello no quiere decir que no existiera antes o después de ese lapso, pero las inscripciones previas son muy pocas y de datación discutible, pues pueden ser perduraciones de cerámica ática de figuras negras. Sí parecen encontrarse, ocasionalmente, inscripciones algo posteriores, pero son muy pocas y de mínima importancia.

${ }^{6}$ En lo referente al signario ibérico meridional es preciso advertir que sigue vigente la desorientadora publicación de lecturas totalmente desfasadas (así en Ruiz, A.; Molinos, M, Los iberos, Barcelona, 1993, 251). Es preferible referirse al signario de los Monumenta Linguarum Hispanicarum III, 1 (= Untermann 1990) o a mi pequeño 'dossier' Breve Manual de Epigrafía Ibérica, Barcelona, 1995, 35-40.

7 La mayor parte de las identificaciones del material de barniz negro de Enserune proviene de Jannoray 1955, por lo que es claramente revisable.

${ }^{8}$ Es la interpretación tradicional del final del poblado de Tivissa, apoyada por la datación de los dos tesoros numismáticos hallados. Si bien se ha señalado la presencia de algún material posterior, lo único que puede suponerse es que la destrucción no fue total o definitiva, pero la experiencia indica que los plomos hallados suelen proceder precisamente de fases de destrucción.
}

con grupos ibéricos desplazados por la invasión romana. Todos los datos apuntan a los inicios del s. II. be-11: 210/200-180/175.

be-13: variante esquematizada de $b e-11$ presente en las inscripciones rupestres de Osseja y Roda de Ter D.3.1; su cronología ha de ser similar a be-11, tal vez con un lapso inferior ligeramente más moderno.

be-14: sobre dos ánforas de Pech-Maho (la 15 y la 26 ; B.7.16 y 27), seguramente de su etapa final de $250-225 / 200^{9}$.

be-8: derivación natural de $b e-10 \mathrm{~b}$ que se encuentra en dos estelas funerarias de Sagunto (F.11.2 y 10) ${ }^{10}$ y en ocho campanienses de Enserune (30, $37,69,168,171,206,207$ y 229; B.1.36, 40, 72, $172,175,210,211$ y 233). La datación de este signo no es precisa, aunque su posición evolutiva y su ausencia en dataciones claras del s. III o post $150 \mathrm{su}$ giere un lapso razonable de 210/200-150.

\section{Formas modernas: (190/175-50)}

be-6: es muy frecuente, pero nunca en piezas que puedan ser anteriores a finales del s. III. Se asocia a campanienses B, B-oides (en Sorba), a estelas funerarias y leyendas monetales, presentando dataciones seguras del s. I. Si bien hay problemas para datar inscripciones de la primera mitad del s. II, todo indica que be-6 es contemporáneo de las campanienses B. be-6: 150-50.

be-7: sus dataciones son imprecisas, pero siempre posteriores al 200, siendo frecuente en inscripciones funerarias y leyendas monetales. Presenta una datación clara de inicios del s. I en el plomo de Gruissan. Ahora bien, su asociación a formas de te y de $s$ de principios o primera mitad del s. II denota su prioridad respecto a be-6. be-7: 190/175-50.

Otros signos son menos reveladores pero aportan información interesante:

Signo $a$ : la forma $a-1$ es una forma clásica que, siendo la originaria, puede aparecer en cualquier época. $a-2$ y $a-3$ marcan un ductus transicional hacia $a-4$.

$a-4$ : es un signo epicórico cuyo dominio se extiende desde el sur de Francia a Ampurias (y aquí en inscripciones no monumentales). El plomo de Gruissan (100-66) es un indicio de su pervivencia, mien-

\footnotetext{
9 Ambas presentan formas de $l$ y $m$ de Neoibérico, lo que confirmaría su datación en la segunda mitad del s. III.

${ }^{10}$ En general el conjunto de las estelas funerarias parece adscribirse a los ss. II-I y en tales términos las suelo datar por defecto, pero las inscripciones sobre piedra de Sagunto pudieran haber empezado ya a fines del s. III.
} 


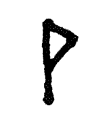

$a-1 a$

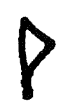

$a-1 b$

$l-1$

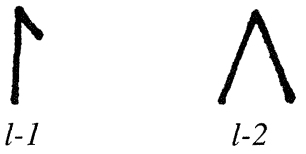

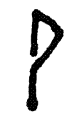

$a-2$

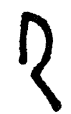

$a-3$

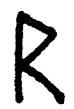

$a-4 a$

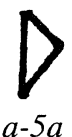

$a-5 a$
R

$a-4 b$

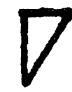

$a-5 b$
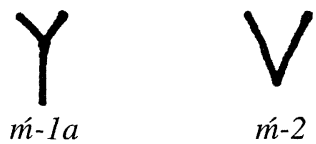

ḿ-2

Fig. 2.-Clasificación de $a, l$ y $\dot{m}$.

tras que el tope superior está indicado por su aparición en la fase final de Pech-Maho (ca. 225) y en las cerámicas Lamboglia 40 de la fase final de la necrópolis de Enserune (325-225), números 20 y 24 (B.1.23 y 27). Todo ello apunta a una cronología de 250-50. De dicha cronología se puede proponer que la forma previa $a-3$ pertenece a un lapso $300 / 275$ 250.

a-5a: signo cuya aparición más antigua se asocia también a la fase final de la necrópolis de Enseru$n \mathrm{e}^{11}\left(\mathrm{n}^{\mathrm{o}} 12 \mathrm{~B} .1 .15\right)$, pero en este caso pudiera tratarse de un mal trazo, ya que aparece con $a-4$. Sí se encuentra en Margalef-02 D.9.2 (s. III?) y en dos inscripciones del nivel antiguo de Liria. Aun teniendo en cuenta que puede aparecer previamente como $a$ mal trazada, parece iniciar su uso a fines del s. III. a-5a: 225/200-50.

$a-5$ b: es un derivado tardío de $a-5$ cuyas cronologías suelen ser de ca. 100. Su aparición en las inscripciones pintadas de Vieille-Toulouse (170130) induce a elevar ligeramente su inicio, si bien el ser escritura pintada puede justificar realizacio-nes más innovadoras y cursivas. $a-5 b$ hace su aparición en la numismática en la fase IV de Sagunto, aunque

1 Es dudosa su identificación sobre una ática de barniz negro (Lamb. 21) de Sidamunt, donde, como en una pieza similar de Sagunto, parece corresponder a una $r$ invertida y corregirse su lectura en kulesurúr. la datación de la misma que hace Villaronga de post 195 no aclara el momento inicial. $a-5 \mathrm{~b}: 150-50$.

Signo $o$ : $o-1$, la forma hachemorfa $(\mathrm{H})$ es, con mucho, la más frecuente, y es una forma clásica. Ahora bien, las formas restantes, más 'adornadas', no parecen superar los inicios del s. II, con yacimientos tales como Tivissa, Liria, Orleyl, Ullastret y Peña del Moro. Una excepción podría ser $o-5$ si es que realmente aparece en la estela funeraria de $\mathrm{Bi}$ néfar, y salvo si dicha inscripción fuese de inicios o primera mitad del s. II.

$o-2, o-3, o-4$ (y $o-5 ?$ ): 400-175.

Signo $l$ : sólo presenta dos variantes relevantes. Mientras $l-1$ es una forma clásica, $l-2$ no presenta cronologías claras previas a finales del s. III, como son los plomos de Pech-Maho (ca. 225) y el plomo Ampurias-23 (250-200, probablemente ca. 210/ 200).

l-2: 225-50.

Signo $r$ : Las formas $r-1$ son las clásicas y las $r$ 2 las innovadas, mientras que en $r-3$ se recogen formas evolutivamente intermedias que no deben ser muy antiguas, pero cuya presencia, al depender demasiado su identificación del tipo de ductus y de la claridad de la inscripción, no siempre se puede asegurar. La aparición más antigua de $r$-2 se identifica en uno de los plomos de Pech-Maho (ca. 225), pero coexistiendo con el normal $r-1$. El resto de los ca- 

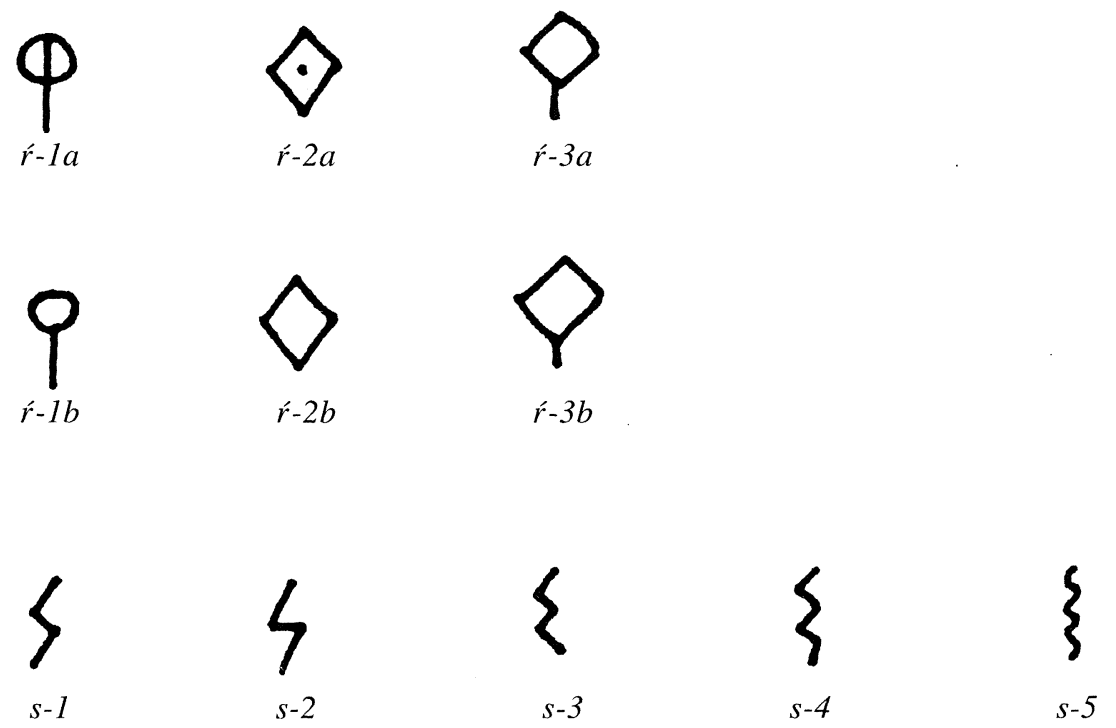

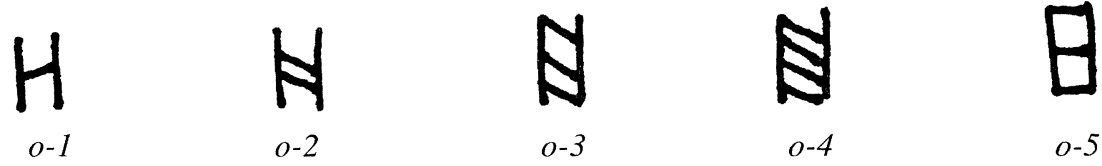
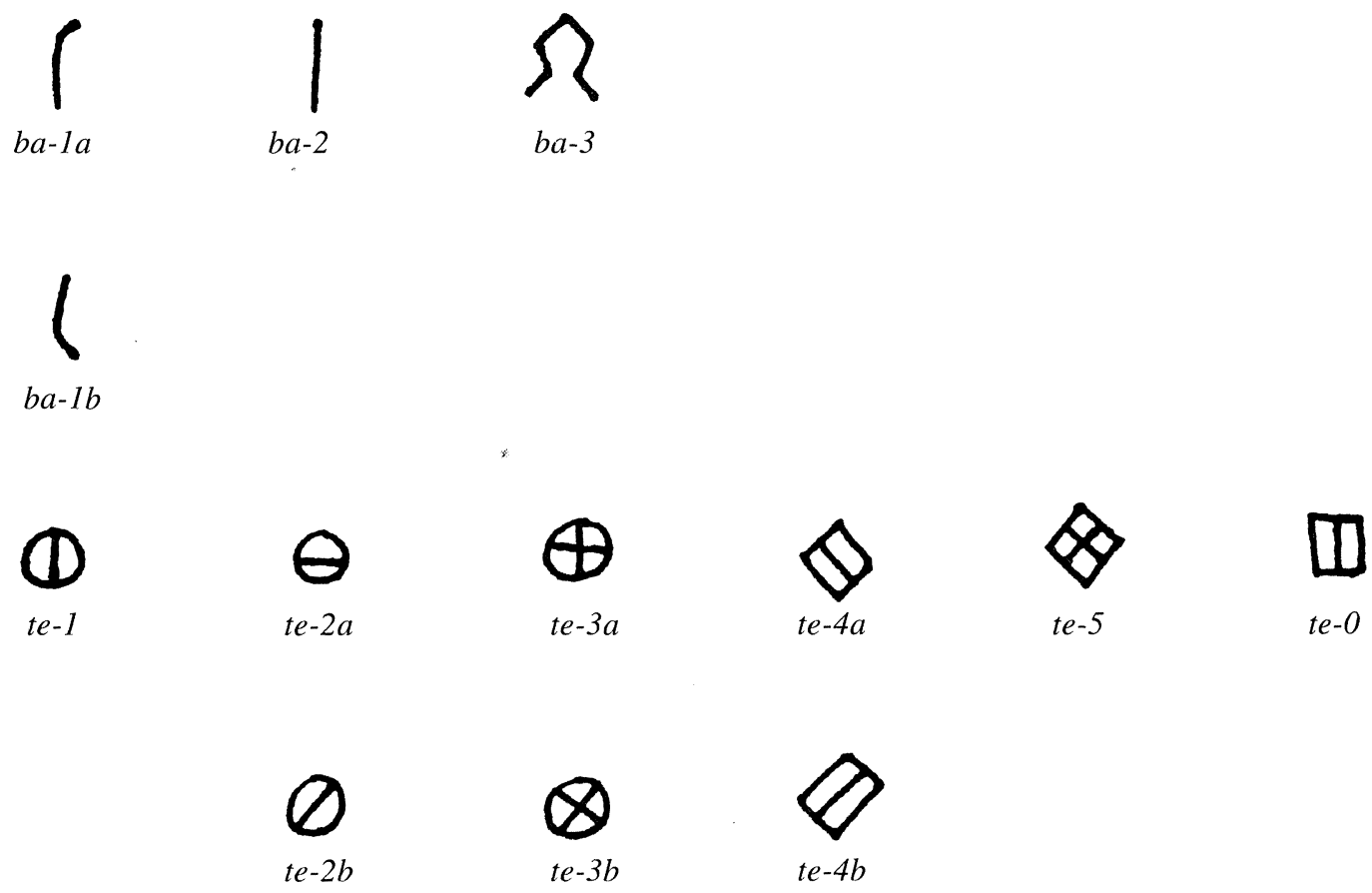

Fig. 3.-Clasificación de $r, s, o, b a$ y te. 
sos es de los ss. II-I, por lo que parece que no se generaliza hasta el 200.

$\dot{r}-2:$ 225/200-50.

Signo $s$ : de acuerdo con lo esperable a partir del signo meridional de origen ${ }^{12}$, el prototipo original ha de ser $s-4$ y su derivado $s$-3. Efectivamente se comprueba que las formas complejas de $s(s-3, s-4$ y $s-5)$ son las más antiguas. Mientras que las formas $s-1$ y $s-2$ son las innovadoras, presentando un predominio absoluto en época iberorromana.

$s-1$ : es una forma moderna. A pesar de ello, se encuentra en dos de los tres plomos de la tumba de Orleyl ${ }^{13}$, cuyo ajuar data de fines del s. Iv, pero que presenta una paleografía de pleno s. III. Exceptuando este problemático testimonio, el resto de sus primeras apariciones es de finales del s. III. Así, como forma secundaria, en los plomos de Pech-Maho, en los que la forma normal es $s-3$. También se encuentra sobre algunas piezas cerámicas de Liria (250180); plausiblemente del segmento inferior del lapso. La impresión que puede tenerse es que, como parece ser el caso en Pech-Maho, en el s. III se trate de una simplificación accidental de $s$-3, mientras que en los ss. II-I ya sea la forma normal, verosímilmente por influjo latino. Su aparición sugiere que probablemente la inscripción sea post 250 o post 225 , y, en todo caso no del s. Iv, pero por el momento no es un documento determinante ${ }^{14} . s-1: 275$ ?/ 250-50.

$s$-2: variante de $s$-1 en que el trazo central es horizontal. Su aparición más antigua se realiza en inscripciones pintadas. Así en tres piezas de Liria (dos de ellas datables en el lapso 250-180), siendo la forma normal en las ánforas de Vieille-Toulouse (170-130). Pero en lo concerniente a inscripciones realizadas por incisión presenta dataciones post 150 (p.e. ánforas Dressel 1 de Azaila) o del s. I (plomo de Gruissan).

En las monedas de Sagunto $s-2$ aparece en la fase IV, que Villaronga considera post 195, en emisiones de mediados y de la segunda mitad del s. II ${ }^{15}$.

\footnotetext{
${ }^{12}$ El signo de origen es la forma de 'samek' de un trazo vertical cruzado por tres horizontales. La evolución que conduciría a la $s$ ibérica levantina, que muestra un mayor parecido con la sigma griega, tiene paralelos en la epigrafía fenicia y se habría producido al escribir los trazos horizontales de forma continua, con sus respectivas líneas oblicuas de conexión entre ellos, en un único trazo zigzagueante.

${ }^{13}$ Curiosamente, los otros dos emplean $s-3$.

${ }_{14}$ Otro caso difícil es Pech-Maho-30 (B.7.31) donde aparecería junto a una especie de $b e-2$. Con todo el signo $s-1$ aparece en una zona fracturada y no excluyo la posibilidad de que se trate de un $s-3$.

${ }_{15}$ Son las $C N H$ Sagunto $n^{\circ} 29,30$ y 32 , de mediados de siglo II; y las $38,39,43$ y 44 , de su último tercio.
}

Al igual que con $a-5 \mathrm{~b}$ si esta aparición fuese próxima al 195 cabría relacionarla con las formas de la cercana Liria. $s$-2: 200-50; predominio en 150-50.

$s$-3: se documenta claramente en el s. IV (plomo de Peña del Moro, cerámicas áticas de Ullastret), en el s. III (plomo de Pontós, barniz negro de la fase final de la necrópolis de Enserune, la forma normal en las cerámicas de Liria) y a finales del III (plomos de Pech-Maho y Ampurias-23); mientras que verosímilmente serían de inicios del II los casos rupestres de Osseja y de Roda de Ter. Su aparición en las estelas funerarias de signario arcaizante de Binéfar y de Sagunto-02 F.11.2 no aclara el momento final de uso, que sería hacia el 175 o el 150. Sin embargo hay que reseñar que entre todas las inscripciones de Azaila se documenta una vez, en Azaila-335 E.1.337, pero datable a principios del s. I (!). Es posible que en este caso se trate de una influencia del signario celtibérico meridional, que usa $s-3$ y es cercano a Azaila.

En las leyendas monetales $s$ - 3 es de raro uso encontrándose en la fase Ia de las series de Sagunto (Villaronga 1967 y $1994{ }^{16}$ ) y en la enigmática ceca belsesalir ${ }^{17}$ en la que aparece con una especie de $b e-11$, lo que la encuadraría en un lapso 210-175. $s-3: 400-175 / 150$.

$s-4$ : su documentación más antigua se halla en la primera mitad del s. III (plomo de Palamós, cista de Pech-Maho-01 B.7.1). Aparece con claridad en el resto del s. III e inicios del II (varios casos en Liria, los dos plomos de Tivissa, los plomos de PechMaho y un caso en Err y otro en Osseja). De los cuatro casos presentes en Enserune sólo puedo datar con precisión el número 250 en la primera mitad del s. II. Asimismo se presenta otro caso único en Azaila-67 E.1.67 (180-75).

En las leyendas monetales levantinas $s-4$ se encuentra en una imitación de dracma ampuritana de s. III (tikirskine) ${ }^{18}$. s-4: 400?/300 - 175/150.

$s-5$ : presencia clara en piezas áticas del s. IV de Ullastret, y en la fase final de la necrópolis de Enserune (24 y 28 B.1.27 y 31) (325-225). Está presente en la fase final de Pech-Maho (250-225/200), siendo muy abundante en Liria (250-180). Su lapso final se puede hallar en tres inscripciones rupestres

${ }^{16}$ En su $\mathrm{CNH}$ aparece en las emisiones de Sagunto de la 1 a la 11, que corresponden a finales del s. III. Esta variante ya no se encuentra en las emisiones saguntinas que Villaronga data a inicios del s. II. En la número 1, el que en la inscripción $n^{\circ} 1$ coexistan $s-3$ y $s-1$ es una errata del $C N H$ como se comprueba en la fotografía.

17 Corresponde en $\mathrm{CNH}$ a las dracmas ibéricas 41a, 65 y 105.

${ }^{18}$ CNH dracma ibérica $\mathrm{n}^{\circ} 73$. 
de Osseja (inicios s. II?) y dos campanienses A (225-100) de Enserune, 37 y 41 (B.1.40 y 44); ambas de formas identificables y ya presentes en la $\mathrm{A}$ antigua (225-180), una de las cuales presenta una forma de be transicional (210-150). s-5: 400- 175/ 150.

Signo $m$ : la forma antigua es la $m-1$ y «oficialmente» haría sus primeras apariciones en el s. III: $\bar{m}$ 1a en los plomos de Orleyl (post 325, ¿ca. 275?) y $m-1 b$ en Liria y en Lamboglias 40 de la necrópolis de Enserune (325-225). Pero ello es debido a que los pocos casos de $m^{\prime}-1 \mathrm{~b}$ datables en el s. IV son corregidos por Untermann como $b a-1$, lo que no encuentro suficientemente justificado ${ }^{19} . m^{\prime}-1: 400-50$ (¿ḿ-1a: 300-50?).

$m$-2: hace sus prístinas apariciones en dos Lamboglias 40 de la necrópolis de Enserune (325-225) ${ }^{20}$ y en el estrato final de Pech-Maho sobre ánforas greco-itálicas LWb de la segunda mitad del s. III. En los ss. II-I pasa a ser la forma dominante. $m^{\prime}-2$ : 250-50.

Signo ba: en este caso se puede comprobar un periodo inicial en el que se usa ba-1 (lógico si lo cotejamos con el $b a$ meridional); una transición, muy mal documentada, en la que coexisten $b a-1$ y 2 en un mismo documento; y, posteriormente, un uso exclusivo de $b a-2 . b a-1$ puede encontrarse con normalidad en las inscripciones del s. IV sobre cerámica ática. Mientras, en el plomo de Palamós, presuntamente de la primera mitad del s. III, pueden encontrarse tanto la forma original como la innovada, lo que sugiere que el periodo de transición sería de ca. 275, aunque, por desgracia, la escasez de documentos fechables con claridad a inicios del s. III no permite una precisión mayor. En inscripciones posteriores a ésta de Palamós únicamente se encuentra la forma $b a-2$.

$b a-1: 425-300 / 275 ; b a-2: 300 / 275-50$.

Signo ke: de las ocho formas de ke identificadas sólo permiten datación las número 1, 2 y 6 . En los restantes casos, o bien están mal atestiguados, como $k e-8$, o se trata de formas clásicas comunes a todos los periodos, como ke-4.

$k e-1$ : dado que en una pieza de Ullastret del s. IV su presencia no es clara, el estudio en primera instancia de la cronología de sus soportes mostraría un inicio de uso ya entrado el s. III con una pieza de barniz negro, Enserune-28 B.1.31, de la última fase

${ }_{19}$ Así en C.3.2., del s. Iv; o en el plomo de Palamós de inicios del s. III.

${ }^{20}$ La 12 y la 24 ; en ambas aparece $a-4$, lo que apoya que estas 'innovaciones' correspondan a la fase final de la necrópolis. de la necrópolis (325-225) y con las inscripciones sobre plomo de finales del s. III de Pech-Maho y Ampurias-23. Ahora bien, su presencia en el plomo de Ullastret junto a be-2 prácticamente demuestra su presencia en la segunda mitad del s. IV. $k e-1$ : 400/ 350-50.

$k e-2$ y su derivado $k e-6: k e-2$ se halla documentado en cerámicas áticas (s. IV), pero interesa que sus últimos testimonios se encuentran en los plomos de Pech-Maho (ca. 225) y en tres inscripciones rupestres de Osseja (inicios del s. II?). ke-6, por su parte se localiza en tres inscripciones de Liria (250180). Parece lógico considerar que ambos pertenecen a un mismo lapso cronológico. Es interesante observar que nunca coexiste con be-7.

En leyendas monetales sólo se encuentra en el unicum saguntino de plata del museo de Estocolmo. Se considera que es la pieza más antigua de esta ceca y sería de fines del s. III ${ }^{21}$. ke-2: 400/350-200/ 175.

Signo te: además de los indicados, merece reseñarse una forma, te-0, que se documenta sólo en dos casos, ambos en piezas del ajuar de la última fase de la necrópolis de Enserune (325-225). Es plausible la relación de esta forma rectangular con $t e-1$.

te-1: la forma circular de eje vertical presenta testimonios de un periodo muy restringido. Son los prístinos aquellos sobre cerámica pintada de Liria (250-180), así como en los plomos de fines del III de Pech-Maho y Ampurias-23. Con reservas, pero plausiblemente de ca. 200 o de inicios del s. II, haría su aparición en las inscripciones rupestres de Carol y Err, así como en el plomo de Tivissa-07, mientras que su presencia en un bicónico de cerámica gris costa catalana dataría de la segunda mitad del s. III. Ahora bien, su parecido con te-2 y la escasa documentación de inscripciones de la primera mitad del s. III invitan a la prudencia. te-1: 250-180.

te-2: como la anterior, está ausente de las inscripciones sobre ática, pero sí se encuentra en el plomo de Peña del Moro que data del s. Iv. Su testimonio final es similar a $t e-1$, apareciendo sobre cerámicas de Liria y en el plomo de Tivissa-06 (inicios del s. II?). Se encuentra también en uno de los plomos de Pech-Maho, pero en aquél donde la forma te presenta cuatro o cinco realizaciones diferentes, producto, quizá, de una caligrafía descuidada, por lo que es difícil decidir cuál era el signo ideal dentro del signario utilizado. te-2: 350/325-180.

te-3 : Forma que se halla tanto sobre cerámica ática, como en el plomo de Peña del Moro, como en

\footnotetext{
21 CNH Sagunto 1.
} 


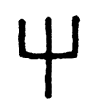

ti-1a

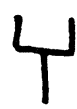

$t i-2$

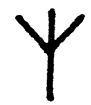

$t i-3$

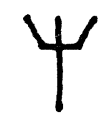

$t i-4$

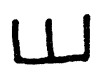

to- $1 a$

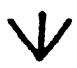

to-2

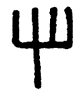

$t i-1 b$

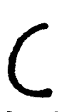

$k e-1 a$

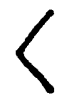

$k e-1 b$

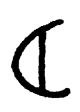

$k e-2 a$

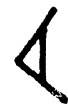

$k e-2 b$

\section{Ш}

to- $1 b$
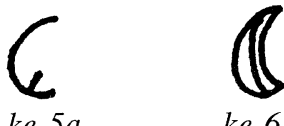

ke-6

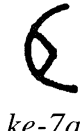

ke-3

ke-5a

$k e-7 a$
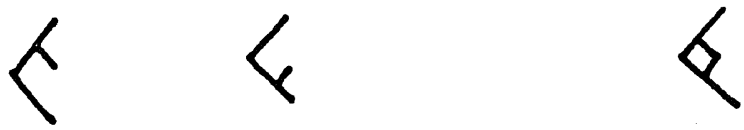

$k e-4 b$

$k e-5 b$

$k e-7 \bar{b}$

$k e-8$

Fig. 4.-Clasificación de $t i$, to y $k e$.

el de Palamós (ca. 27.5), en cerámicas de Liria, en algunos fragmentos de barniz negro de Enserune y en inscripciones rupestres de Osseja. Su ausencia en piezas claras de los ss. II y I, así como su similitud estructural con los precedentes inducen a considerar probable una fecha de desuso parecida. te-3: 400180.

te-4: Su testimonio más antiguo es precisamente el plomo de Pech-Maho (ca. 225) que presenta diversas formas irregulares de $t e$, por lo que su auténtico periodo de uso se documenta con claridad en los ss. II-I. Es común sobre las estelas funerarias, sobre las cerámicas de Azaila, en el mosaico de Caminreal (ca. 100) y en el plomo de Gruissan (inicios del s. I). Aparenta ser el sustituto de las formas redondeadas $t e-1,2$ y 3. te-4: (225?)/200/175-50.

te -5 : forma muy poco frecuente pero atestiguada en diversas épocas y lugares: posiblemente en una ática de Ruscino-05 B.8.5 (s. Iv), en los plomos de Orleyl (ca. 275?), en los de Pech-Maho (ca. 225), y en Azaila (piezas de fines del s. II e inicios del I).

Signos ti y to: ambos signos presentan una evo- lución paralela. Las formas 1a de ambos son clásicas y, por tanto, presentes en cualquier época, mientras que las formas $1 \mathrm{~b}$, de cuatro apéndices superiores, son propias de la notación dual de oclusivas correspondiente a la notación sorda frente a sonora de los textos grecoibéricos. Notación que parece dejar de usarse hacia el $200^{22}$. Ello apuntaría a que las formas $1 \mathrm{~b}$ son siempre anteriores a dicha fecha, pero no resulta descartable su presencia como mera variante fuera del sistema de notación dual de las oclusivas.

ti-1b: empieza su aparición en las cerámicas áticas y tiene un momento final en las inscripciones rupestres de Osseja (inicios del s. II?). Para una mayor concreción haría falta revisar los casos en que aparece en piezas de Enserune identificadas por Jan-

22 Correa (1992: 291) plantea que el sistema sigue en vigor en el s. II; ello es básicamente consecuencia de que algunas inscripciones se han publicado con dataciones absurdas, que Correa ha seguido. Por otra parte C.1.10 no demuestra nada, puesto que usa la forma común. 
noray como «campanienses del primer estilo». También está presente en un minúsculo fragmento de barniz negro de Llinars datado en principio en $250-$ $100^{23}$. $t i-1$ b: $400-200 / 175$.

to-1b: se halla bien documentado en los ss. Iv y III, aunque dos casos provienen de Liria, donde no se considera que haya una notación dual de las oclusivas. Su lapso final, como en el caso precedente, está marcado por una inscripción de Osseja y diversas «campanienses del primer estilo» de Enserune ${ }^{24}$. to-1b: 400-200/175.

ti-3: es básicamente una forma tardía cuyos soportes típicos son campanienses B y estelas funerarias. Sus apariciones mejor datables son ya del s. I (hueso de El Toro-01 F.15.1, plomo de Gruissan, Rubí-01 C.11.1 y Montjuic-2-01). Es por ello difícil decidir si su aparición en Err y Osseja se debe a un mal trazado de los signos, tal vez mala conservación de los signos a causa del desgaste de la piedra, o a que alguna inscripción de este conjunto sería ya de mediados del s. II. Sólo en Osseja-05 aparenta ser signo principal, viéndose claro que en Osseja-03 y 09 es una mala realización de $t i-1$, que predomina, incluso en su variante $1 \mathrm{~b}$. Por lo demás, su aparición más temprana se localiza en los tituli picti de las ánforas de Vieille-Toulouse (170-130). En todo caso se comprueba que, al igual que en $\mathrm{Li}$ ria, las inscripciones pintadas presentan las formas innovadas desde su primer momento.

En las monedas, $t i-3$ hace su aparición en la fase $\mathrm{V}$ de iltirta datada por Villaronga en el periodo 143104 , pero en $\mathrm{CNH}$ ya cataloga las emisiones con este signo como post $104{ }^{25}$. $t i-3$ : $150-50$.

to-2: forma correspondiente a la evolución de $t i$ 3 pero que resulta muy inusual, hasta el punto de que $t i-3$ suele aparecer con to- 1 y que en ocasiones una forma de $t o-2$ en realidad no es más que un $t i-3$ simplificado. Los cinco casos datables, dos de 150 50 y tres de 200-50, no permiten precisiones y cabe suponer que su aparición es ligeramente posterior a la de $t i-3$.

$t i-4$ : forma de transición evolutiva entre $t i-1$ a y $t i-3$. Es poco frecuente y, además, de los trece casos

\footnotetext{
${ }^{23}$ Según información de Panosa, 1992: nº 26.

${ }^{24}$ No es claro, con todo, si la mera presencia de las formas de notación dual $t i-1 \mathrm{~b}$ y $t o-1 \mathrm{~b}$ bastan para datar la inscripción, puesto que no es difícil que ocasionalmente una forma de estos signos se haga accidentalmente con cuatro trazos y, de hecho, existe algún caso tardío en ibérico en que junto a $t i-3$ y to- 1 a se usa de forma muy minoritaria to- $1 \mathrm{~b}$.

${ }_{25}$ Por desgracia en la leyenda monetal no siempre es clara la distinción de $t i-3$. Esta variante se encontraría en las monedas de Iltirta $\mathrm{n}^{\circ} 22$ a 34 y 36 y 37 . En todo caso, $\mathrm{CNH}$ indica emisiones de Játiva de mediados del s. II con esta variante.
}

en que aparece, en ocho son formas de trazado irregular en las que es difícil decidir si realmente lo es. Los datos indican que es posterior al 200 a.C. y dado que está ausente tanto de las inscripciones del s. I como de aquéllas de ca. 200 o inicios del s. II, aparenta, con las debidas reservas, ser una forma propia del s. II, cuya aparición sería, por motivos evolutivos, ligeramente previa a la de $t i-3$.

\section{PERIODIZACIONES}

Es bien cierto que en el material disponible restan incógnitas en demasía que impiden una precisión igual del uso del signario ibérico levantino en todos los períodos y en todas las regiones. Aun así, sabedores de la posibilidad de que determinados signarios innovadores hayan iniciado su empleo antes en unas zonas que en otras, es factible establecer una primera evolución de su cronología relativa y perfilar su correspondencia con cronologías absolutas.

En un primer estadio prima el interés sobre la variedad de formas de $b e$ :

- Fase A (arcaica): 425 - 300: formas 1, 2, 3 y 4.

- Fase B (media): s. III: formas 9 y 10.

- Fase C (transicional): 210/200 - 180/150: formas $8,11,13$ y 14 .

- Fase D (moderna): 190/175- 50: formas 6 y 7.

A su vez puede precisarse una subfase de $D$, que llamaremos $\mathrm{E}$ (final), que parece corresponder a una datación 150 - 50 y sería propia de be-6.

Esta periodización de be es muy útil ya que, a diferencia de la mayoría de los otros signos, no existe una forma clásica de be que, apareciendo sobre una inscripción, no proporcionase información cronológica. No obstante, el análisis conjunto de los signos sugiere una periodización levemente diferente.

Paleorbérico: es la fase previa a las innovaciones de los signos $l, m$ y $a$. Innovaciones que, según el testimonio de la necrópolis de Enserune, tendría lugar ca. 250. Básicamente se usan los signos clásicos y su principal distinción se realiza a través de be y $b a$. Se emplea el sistema de notación dual de oclusivas.

Paleoibérico 1 (425/400 - 300) : corresponde a la fase A, arcaica de $b e$. En ella se utiliza la forma $b a$ 1. Es posible rastrear una subdivisión interna de la fase, tal y como se comentó al tratar las formas arcaicas de be.

Paleoibérico $2(300-250)$ : corresponde al inicio de la fase $\mathrm{B}$, media de $b e$, previa a las innovaciones. Aun con poca documentación puede diferenciarse un Paleoibérico 2a (300 - 275?) en la que se sigue usan- 


\begin{tabular}{|c|c|c|c|c|c|c|}
\hline & Ullastret & Palamós & Orleyl & $\begin{array}{l}\text { Ampurias- } \\
23\end{array}$ & $\begin{array}{l}\text { Pech- } \\
\text { Maho }\end{array}$ & Liria \\
\hline $\begin{array}{l}\text { cronol. } \\
\text { arqueol. }\end{array}$ & $? ?$ & $300-250 ?$ & post 325 & $225-200$ & $250-200$ & $250-180$ \\
\hline fase & $\begin{array}{l}\text { PaleoIb. } \\
I b\end{array}$ & $\begin{array}{l}\text { Paleolb. } \\
2 a\end{array}$ & PaleoIb. 2 & Neolb. 1 & Neolb. 1 & Neolb. 2 \\
\hline $\begin{array}{l}\text { cronol. } \\
\text { propuesta }\end{array}$ & fines s.IV? & $300-275 ?$ & ca. 275?? & ca. 220 & ca. 220 & $200-180$ \\
\hline$a$ & $D$ & & D & & & $P$ \\
\hline$o$ & & & $\mathrm{H}$ & $\mathrm{H}$ & & $\theta$ \\
\hline$b a$ & & & & & & \\
\hline$b e$ & & & & & & \\
\hline te & $\theta \otimes$ & $\theta$ & & & $\begin{array}{l}\theta \oplus \otimes \\
\oplus \diamond \otimes\end{array}$ & (1) $\otimes$ \\
\hline$t i$ & 4 لب & 4 & 4 & 44 & 4 & 4 \\
\hline ke & & & & & & \\
\hline$l$ & & & & & & \\
\hline$\dot{f}$ & & & & & & \\
\hline$s$ & & & & & & \\
\hline$m$ & $N$ & $M$ & & & & \\
\hline$m$ & & & & & & $V$ \\
\hline$?$ & & & & & & \\
\hline
\end{tabular}

Fig. 5a. 


\begin{tabular}{|c|c|c|c|c|c|c|}
\hline & Solaig & Ampurias & Yátova & Gruissan & $\begin{array}{l}\text { tipo } \\
\text { Botorrita }\end{array}$ & $\begin{array}{l}\text { tipo } \\
\text { Luzaga }\end{array}$ \\
\hline $\begin{array}{l}\text { cronol. } \\
\text { arqueol. }\end{array}$ & $\begin{array}{l}\text { pre } \\
150 / 100 \\
\end{array}$ & s. II? & $\begin{array}{l}\text { prob. } \\
\text { ss.II-I? }\end{array}$ & $100-65$ & ----- & - \\
\hline fase & $\begin{array}{l}\text { NeoIb. } \\
2-3\end{array}$ & Iberorrom.1 & Iberorrom. 2 & Iberorrom. 2 & Celtib. $M$ & Celtib. $N$ \\
\hline $\begin{array}{l}\text { cronol. } \\
\text { propuesta }\end{array}$ & ca. 180 & $\begin{array}{l}175 / 150- \\
50\end{array}$ & $150-50$ & $100-65$ & - & --- \\
\hline$a$ & D & & & & & \\
\hline$o$ & & & & & & \\
\hline$b a$ & & & & & & \\
\hline be & & & & & & \\
\hline te & & & & & & \\
\hline$t i$ & 4 & & $V$ & & & \\
\hline ke & & & & & & \\
\hline$l$ & & & & & & \\
\hline$\dot{r}$ & & & & & & \\
\hline$s$ & & 5 & $\zeta$ & 4 & & $\xi$ \\
\hline$m$ & & & & & $M$ & $N=m$ \\
\hline$m$ & $Y$ & & & & & $V=$ \\
\hline$?$ & & & & & & \\
\hline
\end{tabular}

Fig. 5b. 
do $b a-1$, si bien alternando con $b a-2$; y un Paleoibérico $2 \mathrm{~b}(275$ ? - 250) en el que deja de usarse $b a-1$ y se pasa a $b a-2$, desde entonces omnipresente.

Neorbérico: se produce la aparición de las formas innovadas $\dot{m}-2, a-4$ (en la zona nororiental) y, algo posteriormente, la de $l-2$ (ca.225) y quizás $a$ 5 a (ca. 225/200?). Otra innovación, la de $r-2$, no parece extenderse hasta ca. 200. La subdivisión de este periodo coincide en lo esencial con las fases B (su final), C, D y E. De las cuatro fases que se derivan, las dos últimas tienen una personalidad propia y pueden llamarse Iberorromano 1 y 2 .

Neoibérico 1 (250 - 210/200): uso de las formas medias de be y presencia de las innovaciones propias del Neoibérico. Última fase de uso claro del sistema de notación dual de oclusivas.

Neoibérico 2 ( 210/200 - 180/150): breve fase que probablemente, más que sustituir, se solapa entre el final del Neoibérico 1 y el Iberorromano 1. El uso de las formas be-11, 13 y 14 parece muy limitado a inicios del s. II, mientras que $b e-10$ podría extenderse algo más. Es el último periodo de uso de algunas caligrafías antes normales, como son las formas circulares de te $(1,2$ y 3$)$, las formas elaboradas de $o(2,3,4$ y 5$)$, de $k e-2$, mientras que las formas más complejas de $s(3,4$ y 5$)$ son progresivamente arrinconadas por las homólogas a la $s$ latina (cuya aparición anteriormente era esporádica). Da la sensación de que, si no todos, la mayoría de estos signos deja de usarse antes del 175, por lo que esta fase coincidiría, en líneas generales, con el periodo de conquista romana ${ }^{26}$. Ya no se utiliza el sistema de notación dual de oclusivas.

Iberorromano 1 o Neoibérico 3 (190/175 - 50): corresponde a la fase $\mathrm{D}$, especialmente a la utilización de be-7. Básicamente se distingue por la ausencia de las formas que finalizan en la fase previa; aunque existen testimonios de una especie de Iberorromano $1 \mathrm{a}$ en el que $b e-7$ coexiste con alguna de dichas formas. Las formas 'innovadas', propias del Neoibérico, predominan sobre las clásicas.

Iberorromano 2 o Neoibérico 4 (150/135 - 50): es realmente una subdivisión de la fase Iberorromano 1, con la que coexiste, y correspondería a la fase E. En ella aparecen nuevas formas de signos, especialmente las formas simplificadas $t i-3$ y to-2 (esta última de uso marginal), así como $a-5 b$. Es probable que la forma $b e-6$ también sea exclusiva de estas fechas, mientras que, si bien $s$-2 puede encontrarse antes en alguna inscripción pintada, ahora se

26 De acuerdo con las fuentes clásicas las últimas campañas importantes de pacificación en zona ibérica se realizarían en la década $190 / 180$. hace muy habitual y se encuentra también en inscripciones incisas. Este signario es el típico, junto con $t e-4$, de los documentos sobre Campaniense B y ánforas Dressel 1.

\section{EXAMEN DE ALGUNOS DOCUMENTOS ILUSTRATIVOS}

Seguidamente, a modo de ejemplificación, pasaremos al análisis de los signarios de los textos de la fig. 5. Aparte de diez textos, nueve plomos y uno sobre cerámica, añado los de dos bronces celtibéricos que permiten perfilar su relación con los signarios ibéricos levantinos.

$\left.1^{\circ}\right)$ Plomo de Ullastret-03 C.2.3: fue hallado en el estrato de relleno de una fosa medieval que contenía desde cerámica a mano, cerámica ática y protocampaniense a vidriada medieval. Por lo tanto, la única datación posible es de 425 - 190, de acuerdo con las características del yacimiento ${ }^{27}$.

Paleográficamente queda bien definido por la presencia de $b e-2$, que señala una procedencia del s. IV, posiblemente de su segunda mitad. Mientras que la presencia de un $b a-2$ frente al común $b a-1$ parece accidental. Estos dos signos ya lo califican como Paleoibérico $1 \mathrm{~b}$, lo que junto a la presencia de $k e-1$ establecen su datación más probable ca. $325 \pm 25$. El resto de los signos, o bien es clásico o anterior al Iberorromano 1, es decir pre 175 ( $k e$, te, $s)$.

$2^{\circ}$ ) Plomo de Palamós-01 C.4.1: los descubridores de este plomo consideran que ha de datarse en la primera mitad del s. III ${ }^{28}$. Esta datación encaja bien dentro de la secuencia paleográfica y se fundamenta en los materiales del estrato del que parece provenir, pero debe aclararse que el plomo en cuestión apareció en un derrumbe accidental y no en la excavación regular.

Se advierte la presencia de $b e-9$, una forma media de be de s. III y la clara alternancia de las formas $b a-1$ y $b a-2$. Es, pues, paleográficamente el texto más arcaico de las formas medias de be, lo que sugiere una datación de inicios del s. III o primera mitad, pero faltan materiales de datación segura de cotejo. Corresponde a la fase Paleoibérico $2 \mathrm{a}$.

$\left.3^{\circ}\right)$ Plomo de Orleyl-04 F.9.5: hallado en la tumba II de Orleyl con ajuar ático, cuyo ejemplar más moderno sería de ca. $325^{29}$. Presenta tres pie-

\footnotetext{
27 Oliva, 1967: 107 ss.

28 Riuró, 1982.

${ }^{29}$ Lázaro, Mesado, Aranegui, Fletcher, 1981.
} 
zas de cerámica ática reconocible. Una cílica 'inset lip' (450-350) que fue inhumada ya rota y sin asas. Una cratera de campana con asas, de figuras rojas de estilo Kertch decorada con escena de lucha entre grifos y arimaspos (375-325). Y una ática forma Lamboglia 21 que sus excavadores comparan con el ejemplo 835 de Sparkes-Talcott del Ágora de Atenas de ca. 325. La datación es compleja. El ajuar de la tumba establece un post quem y, aunque la Lamboglia 21 pudiera ser más antigua de lo publicado, sería razonable datar la inhumación a finales del s. IV. Pero los signos de las inscripciones son claramente más modernos que aquéllos que aparecen sobre cerámica del s. IV.

En él ya no aparece la forma antigua de $b a$ y se usa la forma media de $b e$, be-10. Por su parte $l$ muestra los inicios de su evolución a la forma lambda y aparece el testimonio más antiguo de $s$-1; aunque dos de los tres plomos usan $s$-3. Dado que las innovaciones del neoibérico no son de uso obligatorio, su ausencia no es probatoria, por lo que su datación paleográfica más probable sería la de ca. $250 \pm 25$. Pero las pocas inscripciones conocidas de la primera mitad del s. III y el ajuar sugieren que una fecha más prudente sería la de ca. 275 (?). Sin total certeza, parece ser un ejemplo de Paleoibérico 2.

$4^{\circ}$ Plomo Ampurias-23: hallado en un estrato donde predominaba la cerámica protocampaniense de Rosas y había alguna Campaniense A antigua. Es datado por Sanmartí (1988) a finales del s. III o inicios del II. Las producciones del taller de Rosas se datan siempre en $300-225$, por lo que parece prudente hacer una datación más amplia de 250/225200.

En el aspecto paleográfico puede constatarse la forma media $b e-10$, propia del s. III, mientras que ya encontramos la forma innovada $l-2$, que indica un post 225. Obsérvese también la presencia de $t e-1$, el cual, hasta el momento, sólo se documenta en un margen muy estrecho de 250 a 180 . Finalmente, el uso del sistema de notación dual apunta con reservas a un pre 200. Queda por tanto una datación del último cuarto del s. III, posiblemente ca. 220/210. Es clara su adscripción al Neoibérico 1.

$5^{\circ}$ ) Plomos de Pech-Maho 33-36: proceden de un estrato de destrucción de finales del s. III que suele relacionarse más con agresiones de pueblos celtas que con la guerra púnica. En todo caso no parece que se produjesen muy a finales del siglo.

Presenta otra vez el típico be-10 de s. III y las innovaciones de $l-2$ y $\dot{m}-2$, siendo muy similar al plomo Ampurias-23. A diferencia de éste, presenta la forma $a-4$, indiketa-sordona, que sí se encuentra posteriormente en Ampurias en el s. II, pero que parece tener un origen claramente del sur de Francia. Respecto a la forma de $t e$, predominan las formas circulares, como corresponde al s. III, por lo que la aparición de algún te-4 puede deberse a un mal trazado ${ }^{30}$. Obsérvese el notable parecido existente entre el signo de lectura desconocida de Pech-Maho y el de Palamós: se trata seguramente de la evolución posterior de la forma hallada en Palamós. Los plomos de Pech-Maho, en los que se halla presente también la notación dual, han de ser aproximadamente coetáneos al de Ampurias-23, dado que sus diferencias parecen más de diagrapsia ${ }^{31}$ que cronológicas, por lo que les corresponde un. 225-200, clasificándose en el Neoibérico 1.

$6^{\circ}$ ) Cerámica de Liria-03 F.13.3 («vaso de los letreros»): procede de la zona de Liria que de acuerdo con Bonet es destruida a inicios del s. II. Dentro del lapso atribuido a las cerámicas de Liria de este sector (250-180), éste corresponde a la caligrafía más moderna, por lo que puede proponerse una cronología de 210/200 - 180.

Este documento, si bien contiene signos silábicos que presentan dos o tres formas, no se ha podido explicar como perteneciente al sistema de notación dual. Su signario, aún con las reservas lógicas de tener un ductus pintado en vez de inciso, al presentar las formas redondeadas de $t e$, con $s-4, k e-6$ y una forma compuesta de $o$, ha de ser pre 180. La forma más decisiva es la transicional be-11, lo que sugiere una cronología de inicios del s. II y lo adscribe al Neoibérico-2.

$7^{\circ}$ ) Plomo de Solaig-01 F.7.1: el yacimiento de origen, hasta donde tengo noticia, no ha sido excavado, pero sí se han realizado algunas prospecciones que indican que presenta un único estrato muy pequeño con muestras de una destrucción violenta y se identifican algunos fragmentos de Campaniense $\mathrm{A}$, de los que se dibuja una base con roseta central $^{32}$. El material sugiere, por tanto, una breve ocupación pre 100 o incluso pre 150 , mientras que los rastros de incendio final sólo permiten especular, y poco más, sobre si corresponde o no a la represión romana, cuyas acciones importantes concluyen hacia el 180.

En el aspecto gráfico, la presencia de $s-4 \mathrm{y}$, sobre todo, te-2 sugieren un pre 180 , aunque menos firme que en el ejemplo de Liria al faltar $k e-2$

30 Apréciese, con todo, la existencia en la necrópolis de Enserune de dos piezas con una variante rectangular de $t e-1$, clasificada como te- 0 .

31 Un diagrapso es a la escritura lo que un dialecto a la lengua.

32 Fletcher, 1967 
o su variante $k e-6$. Sin embargo, la forma de be no es transicional, sino la normal en época iberorromana $b e-7$ (que en el fondo no es más que una simplificación de $b e-11$ ). Todo ello induce a pensar que recoge el momento final del uso de sus variantes de $t e$ y $s$ y el inicial de $b e-7$ lo que permite suponerle una datación de ca. 180. Tipológicamente corresponde al tránsito del Neoibérico 2 al Iberorromano 1.

$8^{\circ}$ ) Plomo de Ampurias-06 C.1.6: fue hallado junto al Asklepieion, pero, por desgracia, al recoger tierra para tapar un mosaico «debajo de los muros que cubren el corredor de salida trasero de dicho templete». De acuerdo con las últimas excavaciones hechas en la zona, parece que hay que descartar la datación inicial de ss. IV-III ${ }^{33}$. Si nos atenemos a su relación con la edificación del muro, vemos cómo, de acuerdo con Sanmartí y Nolla, la edificación del Asklepieion se corresponde con la ampliación de la ciudad al construir la muralla de mediados del s. II, y que previamente sólo hay indicios de un altar que, en todo caso, estaría extramuros. Ello hace plausible suponer que su estrato de aparición corresponde a los rellenos de base para la edificación en la segunda mitad del s. II ${ }^{34}$.

Presenta claramente signos post 225 de la innovación del Neoibérico ( $l-2$ y $a-4)$, si bien no hay constancia de que $a-4$ aparezca en Ampurias antes del 200. También se encuentra un claro caso de $r-3$. No parece haber uso del sistema de notación dual, lo que, en esta zona, sugeriría un post 200. Asimismo, es de los ss. II-I la forma $s$-2, e incluso preferiblemente post 150 . Por su parte be-6 lo pondría claramente en la última fase del signario ibérico, pero presenta un problema, que, aunque no es insoluble, sí hay que tener en cuenta. La identificación de be6 depende de la reconstrucción del onomástico nal$b e$, cuyo único paralelo claro procede de una única versión latina del nombre en el bronce de Ascoli ${ }^{35}$ y para el cual hay que suponer, en nuestro plomo, la presencia de un único caso de $l-1$ frente al claramente presente $l-2$. Si nos basamos en be-6 juntamente con $s-2$, hipótesis que, a título personal, considero más probable, el plomo dataría de 150-50, mientras que, si rechazamos la presencia de $b e-6$, el lapso superior tendría que ser más flexible 175/15050. La ausencia del signo $t i-3$ no parece ser un ar-

\footnotetext{
33 Almagro, 1951: 103 ss.

${ }^{34}$ Sanmartí, Nolla, 1988: 21 ss.

35 La existencia de un fragmento cerámico con el texto lílbe es susceptible de ser usado tanto a favor como en contra (argumentando que muestra una grafía distinta como base de origen de la forma latina). Cfr. también C.3.2 milbeier.
}

gumento decisivo. Por las mismas causas su adscripción puede ser Iberorromano $1 \mathrm{o}$, preferiblemente, Iberorromano 2.

$\left.9^{\circ}\right)$ Plomos de Yátova 1-3 F.20.1-3: estos tres plomos fueron hallados por un particular, por lo que no hay un contexto arqueológico fiable. Se dice que en la zona apareció también un fragmento de cerámica ática de barniz negro, pero lo relativamente interesante es la indicación de que había una boca de ánfora republicana «en las proximidades» ${ }^{36}$. Por ello con muchas reservas puede sugerirse, a priori, que pertenece a un estrato de romanización ya avanzada. Pero sólo como un indicio más, puesto que como prueba es muy endeble.

Ahora bien, el signario de esta inscripción es muy coherente con esta datación. Se encuentran las formas innovadas de Neoibérico $l-2$ y $m-2$, y, si bien la presencia de $b e-7$ da un lapso amplio de 180-50, al igual que te-4, la forma tardía $s-2$ apunta a un post 150 , cosa que $t i-3$ ratifica. Su cronología es, por tanto, de 150-50 perteneciendo el signario al Iberorromano 2.

$10^{\circ}$ ) Plomo de Gruissan: excepcionalmente se dispone de una cronología muy precisa para este plomo, ya que procede de un conjunto cerrado, de los restos de un barco naufragado ante la playa de Gruissan. Esta datación sería del primer tercio del s. I ${ }^{37}$.

Las formas son las esperadas en un documento del sur de Francia ${ }^{38}$. Presenta la clara diagrapsa de $a-4$ y las formas normales del Iberorromano-2 como son $s-2$ y sobre todo $t i-3$. El signario utilizado es muy similar al de los plomos de Yátova, salvo la lógica excepción de la forma local de $a$ y la presencia de la forma romboidal $\dot{r}-2$, alternancia habitual en los ss. II-I.

Expuestos, de la manera precedente, los principales rasgos de la evolución paleográfica de la escritura ibérica levantina, resulta interesante compararla con la de sus derivados más inmediatos en la escritura celtibérica.

En la columna $11^{\mathrm{a}}$ podemos ver los signos habituales en la escritura celtibérica que podemos ejemplificar en el bronce de Botorrita y que provisionalmente podemos llamar septentrional o celtibérico M. En él podemos constatar una serie de formas clásicas de escaso valor cronológico, como son los signos usados para $o, t i, k e, l$ y $m$. Formas como $b a-2$ o $r$-3 sugieren un previsible post 275 , pero el resto de las formas son claramente iberorromanas. La

\footnotetext{
36 Fletcher, 1966: 6.

37 Solier y Barbouteau, 1988.

38 Claro está que el punto de naufragio de un buque no ha de corresponder necesariamente con su lugar de origen, pero en este caso no debía ser lejano.
} 
aparición alternativa de $t i-4$ lleva a pensar en el tránsito hacia $t i-3$ que empezaría con el s. II. Por su parte, te-4 es básicamente un signo post $180 \mathrm{y}$, pese a la ausencia de $t i-3$, están todos los signos típicos del Iberorromano- 2 como son $a-5 b, s-2$ y $b e-7$. Es evidente, por la ausencia de signos que hacen su última aparición en el Neoibérico 2, su posterioridad al 175 y bastante probable que el signario ibérico de adaptación fuera una variante del Iberorromano 2 y que, consecuentemente, el origen de esta variante septentrional de celtibérico se date a mediados o en la segunda mitad del s. II.

En la columna $12^{\mathrm{a}}$ tenemos el signario propio de inscripciones del tipo de las de Luzaga, que podemos llamar celtibérico meridional o celtibérico N. En ellas, contrariamente a nuestra manera de transcribir el ibérico, el signo ibérico para $n$ se utiliza para notar una nasal labial $/ \mathrm{m} /$, mientras que el signo $m$, nota la nasal dental $/ \mathrm{n} /$. Ello ha de ponerse en relación con el hecho de que no todos los signarios de ibérico levantino utilizaban el signo $m$, empleando en su lugar, por lo menos en alguna ocasión, el signo $n^{39}$. Seguramente el modelo de ibérico levantino que se utilizó no disponía de $m$. En comparación con Botorrita, los signos del modelo Luzaga son totalmente diferentes: no se utilizan formas del Iberorromano, sino del Neoibérico 1-2. De un lado, la forma de $\dot{m}$ es la innovadora post 250 , de otro, te-3 y $s-3$ y 4 son formas pre 180. La forma de be es de escasa ayuda, ya que puede proceder tanto de $b e-7$ como de $b e-8$; esta última, a mi parecer, más probable formalmente y más coherente con el resto del signario. Finalmente la forma $t i-4$, que denota el inicio de la transición a $t i-3$, apunta, aunque con escasa convicción, a una primera mitad del s. II. Todo ello sugiere que el signario de origen es una forma del Neoibérico2 y que seguramente su adaptación se realizó a inicios del s. II.

\section{ANEXO: DATACIONES DE LAS INSCRIPCIONES}

Azaila: El grueso de las cerámicas de Azaila parece datable en el lapso 150-75. Predominan claramente las campanienses B y las ánforas Dressel 1, mientras que las campanienses no clasificadas corresponden a formas que inician su producción tras

${ }^{39}$ Así en Liria, donde se conoce el uso abundante de $m$, el formante onomástico unin aparece en alguna ocasión escrito umin. Es posible que existiesen otras formas alternativas de escribir $m$ en los signarios que no lo utilizaban, y, en todo caso, sigue sin estar clara la realidad fonética que se oculta en estas grafías. el 180. No es descartable que exista alguna inscripción previa y he preferido mantener un post quem global de post 200, pero el signario de las más de cuatrocientas inscripciones de Azaila es muy uniforme.

Azaila-67 = E.1.67: cerámica campaniense forma 5 ó 7, según Beltrán y la descripción de Untermann (180-50).

Azaila-335 = E.1.337: ánfora itálica Dressel 1b según Beltrán.

El Toro-01 = F.15.1: fechado según las observaciones de la datación del yacimiento de Oliver (1978) en la primera mitad del s. I a.C.

Enserune: Hay dos dataciones estratigráficas claras. Según la primera, la fase III del poblado corresponde a una ampliación/reconstrucción de finales del s. III ya que presenta material campaniense antiguo y así fue datada por Jannoray (1955). Este estrato se asienta sobre la fase final de la necrópolis que Jannoray hacía finalizar hacia el 250 , aunque las nuevas valoraciones de los materiales invitan a seguir la estimación de Schwaller (1994: 69-73) que indica que la necrópolis finaliza a fines del s. III; por ello considero la fecha 225 como ante quem para los materiales de la necrópolis. En algunos casos Jannoray indica una breve fase inicial de la fase III del hábitat cuyas piezas dato en 225-175.

Por lo demás, la complejidad y vastedad del material procedente de Enserune y el que gran parte de él no haya sido reestudiado desde la publicación de Jannoray (1955) hace que la diferenciación entre campanienses y protocampanienses sea revisable y se haya considerado de forma prudente. Me consta, con todo, que Jannoray sí distingue la cerámica del taller de las pequeñas estampillas («italiota»). Finalmente, hay una serie de crateras de barniz negro, áticas y protocampanienses que suceden en el ajuar a la cerámica de figuras rojas cubriendo un lapso de 325-225 (325-250 según Jannoray). Buena parte de ellas presenta decoración de gallones, que, estando ausente de un yacimiento como el de Bastida de les Alcuses, destruido a fines del s. Iv, viene a reforzar el post quem.

Enserune-12 = B.1.15: cratera Lamboglia 40 decorada con gallones procedente de la necrópolis. Es similar al ejemplo 704 de Sparkes-Talcott del Ágora de Atenas (320/310). Asimismo se asemeja a la forma Morel 3521a4 (370-310). De acuerdo con la presencia de los gallones sería una producción ática de la segunda mitad o finales del s. IV. Sin embargo, en cuanto a soporte epigráfico, ha sido reutilizada. Presenta una inscripción ilegible sobre la que se ha escrito otra marca de propiedad con unos caracteres que yo dataría en la primera mitad del s. III (Pale- 
oibérico 2). En otro lugar de la pieza aparece otra marca de propiedad del mismo individuo (auetirisis) pero en caracteres ya de neoibérico. Dado este uso múltiple prefiero dejar su datación en el global de 325-225.

Enserune-20 = B.1.23: cratera de barniz negro, posiblemente una Lamboglia 40 procedente de la necrópolis. Muestra indicios de haber sido reparada antes de inhumarla. Datable en 325-225.

Enserune-22 = B.1.25: cratera Lamboglia 40 procedente de la necrópolis, parece corresponder a la forma Morel $3521 \mathrm{a} 4$ (375-315); pudiera ser una perduración, pero parece probable precisar su datación en 325-275.

Enserune-24 = B.1.27: cratera Lamboglia 40 procedente de la necrópolis que, de acuerdo con el material gráfico de Mouret (1927, n 4), es similar a la forma Morel 3533a1 que Morel considera una producción etrusquizante que en Aleria se asocia a la producción del taller de las pequeñas estampillas. Ello permitiría datarla en 325-250 pero, dado que la pieza fue reparada en la época, parece preferible mantener la datación genérica de 325-225.

Enserune-28 = B.1.31: cratera de barniz negro posiblemente Lamboglia 40 procedente de la necrópolis y que consecuentemente adscribo al lapso $325-$ 225.

Enserune-30 = B.1.33: campaniense de $1^{\text {er }}$ estilo para Jannoray, A para Bats (225-100).

Enserune-37 = B.1.40: campaniense de $1^{\text {er }}$ estilo (Jannoray), A (Maluquer $\mathrm{n}^{\circ} 38$ ), posiblemente una forma 25 o 27a-b (225-100).

Enserune-41 = B.1.44: campaniense A Lamboglia 42B, según Gallet (1980: 56). Datable en 225100.

Enserune-46 = B.1.49: campaniense según Untermann.

Enserune-69 = B.1.72: campaniense según Untermann (225-50).

Enserune-168 = B.1.172: campaniense, pequeño fragmento, según Untermann.

Enserune-171 = B.1.175: cuenco campaniense $1^{\text {er }}$ estilo (Jannoray), A (Maluquer 48) (225-100).

Enserune-178 = B.1.182: campaniense según Untermann.

Enserune-206 = B.1.210: campaniense según Untermann (225-50).

Enserune-207 = B.1.211: campaniense según Untermann (225-50).

Enserune-229 = B.1.233: campaniense $2^{\circ}$ estilo (Jannoray), B (Maluquer 216). En principio un 15050 pero, dado que se trata de un fragmento pequeño y que presenta dos signos (be-8 y te-4) que nunca se asocian a cerámicas post 150 , creo que se trata de una identificación errónea.

Enserune-250 = B.1.254: cerámica de la clase costa catalana, forma Aranegui 4, Dicocer Gb4 datable en la primera mitad del s. II.

Liria: De acuerdo con los estudios de Bonet (1992) el sector alto del poblado, básicamente los cien primeros departamentos, es destruido a inicios del s. II, puesto que el material más moderno que presenta es campaniense A antigua. Asimismo concluye, por comparación con los yacimientos vecinos, un post quem para la cerámica pintada de estilo Liria del 250 a.C. Este lapso (250-180) sirve para la mayor parte de las inscripciones pintadas de Liria, que procede del sector destruido.

Margalef- $02=$ D.9.2: pesa de telar hallada fuera de contexto, pero el grueso de los materiales comparables del yacimiento corresponden al s. III. En todo caso Margalef es destruido hacia el 200 (Junyent, 1972: 130).

Montjuic-2-01 = Panosa.13.1: campaniense $\mathrm{B}$ Lamboglia 1 en contexto del s. I, según Panosa.

Pech-Maho: En este yacimiento se identifica un estrato final previo a la destrucción con ánforas grecoitálicas LWb («tipo Pech-Maho»), cerámica protocampaniense del taller de Rosas y muy poca campaniense A antigua (formas 27, 31 y 36. Solier, 1978). A esta fase, datable consecuentemente en la segunda mitad del s. III, corresponden las inscripciones sobre plomo 33 a 37, así como sobre el dolium PM-32 y las ánforas grecoitálicas 10, 11, 12, 13, 14, $19,20,22$ y 23.

Pech-Maho-1 = B.7.1: inscripción sobre cista de piedra que Solier (1968) data en el s. III, considerando más probable su primera mitad.

Peña del Moro-01 = C.17.1: plomo inscrito procedente de la fase final de este yacimiento que Barberá y Sanmartí (1978) datan en 375-325. Con todo la reciente reevaluación de algunas cronologías áticas hace rebajar un poco la fecha final y cuando se cita esta fase se considera que acaba a fines del s. IV, de ahí un lapso 375-300.

Pontós-02 = C.3.2: base de escifo ático, que Panosa data a inicios del s. Iv.

Rubí-01 = C.11.1: imitación de campaniense B de la primera mitad del s. I según Barberà y Sanmartí (1986: 88).

Ruscino-05 = B.8.5: base de cerámica ática (Untermann), posiblemente de un escifo.

Sorba: Los soportes cerámicos de las inscripciones de Sorba son descritos en Sanmartí 1976, encuadrándose todas en un lapso de 150/125-50.

Tivissa: yacimiento de datación problemática dado que sus excavaciones son antiguas y muchos 
de sus materiales se han perdido. Tradicionalmente se ha venido relacionando su destrucción con las operaciones anti oppida de Catón (ca. 195), política poco compatible con las complejas fortificaciones que presenta. Pallarés (1982: 219) indica que lo poco conservado sugiere que se inicia la ocupación hacia el 450 a. C. y que acabaría hacia el 218. En todo caso los tesorillos numismáticos encontrados, compuestos principalmente por imitaciones ibéricas de dracmas ampuritanas, pero también con ases romanos posteriores al 211, apoyan esta interpretación. Guadán (1969: tesoro $\mathrm{n}^{\circ}$ 69) data uno como anterior al 180, mientras que Villaronga (1967) los incluye como procedentes del periodo 212-195. Consecuentemente, puede considerarse un ante quem de 195 para sus inscripciones, así como es verosímil que los plomos escritos correspondan al momento de destrucción.

Ullastret-05 = C.2.5: plomo procedente del Campo Alto de Sagrero corte central 3, estrato II (Oliva 1953: 306). Aunque este estrato está directamente bajo el superficial, el único material reconocible que indica Oliva es cerámica «griega» de figuras rojas, básicamente escifos, lo que hace más verosímil, con reservas, una datación del s. IV.

Ullastret-17= C.2.17: base de cerámica claramente ática, posiblemente de un escifo (ática en Maluquer $\mathrm{n}^{\circ} 14$ ).

Ullastret-22 = C.2.22: base de cerámica ática del corte de Campo Grande Sagrera Oeste cata 1 estrato II. Publicada como campaniense por Oliva (1960: $68=408$ ) y por Untermann, así como «campaniense antigua» del s. IV o primera mitad del III por Maluquer $\left(n^{\circ} 13\right)$, es claramente, tanto por los círculos de la base como por la decoración de palmetas entrelazadas y estrías del fondo, una pieza ática.

Ullastret-23 = C.2.23: fragmento de base de cerámica ática, así indicada por Untermann y comprobable por la decoración del fondo externo.

Ullastret-25 = C.2.25: fragmento de base de cerámica ática. Mismos datos que en 23.

Ullastret-33 = C.2.33: corte central 2, estrato II fragmento de base de escifo ático (Oliva 1960: $69=$ 409).

Ullastret-34 = C.2.34: fragmento de base de escifo ático de figuras rojas, del sector Frigoleta, corte 2, estrato VI (Oliva 1960: $68=408$ ).

Vieille-Toulouse: Casi todas las inscripciones de Vieille Toulouse (VT 1 a 36) corresponden a un conjunto muy homogéneo de ánforas grecoitálicas con inscripciones pintadas. Vidal y Magnol (1983) las clasifican como del tipo Republicanas 1 de Benoit y consideran que hay que datarlas en el segundo cuarto del s. II (175-150/140). La documentación gráfica que aportan es escasa, pero el ánfora que presentan parece similar al modelo LWe (175-100). Ahora bien, la pormenorizada relación de las formas de las piezas de barniz negro en la clasificación de Morel invita a rebajar algo las dataciones, ya que el grueso del material de barniz negro data de hacia el $160 / 150$ o del $140 / 130$, a lo que hay que añadir que la cerámica de barniz negro suele perdurar más tiempo en uso que las ánforas. Por ello creo plausible datarlas en el lapso 170-140/130.

\section{BIBLIOGRAFÍA}

Almagro, M., 1951: Nueva inscripción ibérica de Ampurias, Zephyrus, II, 103-107.

Barberá, J. ; Sanmartí, E., 1978: El plom ibèric de la Penya del Moro de Sant Just Desvern (Barcelona) i el seu context arqueològic, Riv. St. Liguri XLIV, 145-160.

Beltrán, M., 1976: Arqueología e historia de las ciudades antiguas del Cabezo de Alcalá de Azaila (Teruel). Zaragoza.

Beltrán, M., 1995: Azaila. Nuevas aportaciones deducidas de la documentación inédita de Juan Cabré Aguiló. Zaragoza.

Benages, J., 1990: Escriptura ibèrica sobre plom, Butlletí Arqueològic de la Real Societat Arqueològica Tarraconense, V, 12, 41-43.

Bonet, H., 1992: La cerámica de Sant Miquel de Lliria: su contexto arqueológico, en La sociedad ibérica a través de la imagen, 224-236. Madrid.

Correa, J. A., 1992: Representación gráfica de la oposición de sonoridad en las oclusivas ibéricas (semisilabario levantino), AISN-L, 14 253-291.

FletCher, D., 1966: Los plomos ibéricos de Yaátova $($ Valencia $)=\operatorname{SIP} 66$.

GuadÁn, A. M., 1969: Numismática ibérica e iberoromana. Madrid.

Jannoray, J., 1955: Ensérune. Contribution à l'étude des civilisations prérromaines de la Gaule Méridionale. Paris.

JUNYENT, E., 1972: Los materiales del poblado ibérico de Margalef, en Torregrossa (Lérida), Pyrenae, 8: 89-132.

Lázaro, A.; Mesado, N.; Aranegui, C.; Fletcher, D., 1981: Materiales de la necrópolis ibérica de Orleyl (Vall d'Uxó, Castellón) $=$ SIP 70.

Maluquer de Motes, J., 1968: Epigrafía Prelatina de la Península Ibérica. Barcelona.

Oliva, M., 1953: Actividades de la Comisaría Provincial de las excavaciones arqueológicas de Gerona en 1953, AIEG, 8: 296-327. 
Oliva, M., 1967: Actividades de la Delegación de Excavaciones y del Servicio Provincial de Investigaciones Arqueológicas, Conservación y Catalogación de Monumentos de la Excelentísima Diputación de Gerona en 1960, AIEG, 14: 341-416.

Oliver, A., 1978: Epigrafía ibérica de la provincia de Castellón, CPAC, 5: 265-291.

Pallarés, R., 1982: El Castellet de Banyoles, Tivissa, Les excavacions arqueològiques a Catalunya als darrers anys. Barcelona.

Panosa Domingo, Mª. I., 1992a: L'escriptura ibèrica al nord-est peninsular $i$ el seu marc sòcioeconòmic entre els segles IV i I aC, (tesis microfilmada). Bellaterra.

Panosa Domingo, Ma . I., 1992b: Catàleg i anàlisi dels epigrafs ibèrics del Vallés Oriental, Limes, 2, 57-75.

Panosa Domingo, Ma ${ }^{a}$ I., 1993: Nuevas inscripciones ibéricas de Cataluña, Complutum, 4, 175 222.

RiURo, F., 1982: El plom amb epigrafia ibèrica del poblat de Castell (Palamós), Cypsela, IV, 123-131.

Rodríguez Ramos, J., en prensa: Análisis de Epigrafía Íbera. Barcelona.

SAnmartí-Grego, E., 1976: Breu aproximació a la ceràmica de vernís negre del poblat de Sant Miquel de Sorba, Cypsela, 1: 125-128.

SANMARTí-Grego, E., 1988: Una carta en lengua ibérica escrita sobre plomo, procedente de Emporion, Revue Archéologique de Narbonnaise, 21: 95-113.

Sanmartí, E.; Nolla, J. Mª., 1988: Ampurias. Guía itineraria. Barcelona.

Schwaller, M., 1994: Structures de couverture de signalisation des tombes du deuxième Age du Fer en Languedoc occidental, D.A.M., 17: 69-73.

SolIER, Y., 1979: Découverte d'inscriptions sur plombs en écriture ibérique dans un entrepôt de Pech-Maho (Sigean), Revue Archéologique de Narbonnaise, XII: 55-123.

Solier, Y.; Barbouteau, H., 1988: Découverte de nouveaux plombs, inscrit en ibère, dans la région de Narbonne, Revue Archéologique de Narbonnaise, 21: 61-94.

UntermanN, J., 1980: Monumenta Linguarum Hispanicarum. Bd. II: Die Inschriften in iberischer Schrift aus Südfrankreich. Wiesbaden = MLH II.

UntermanN, J., 1990: Monumenta Linguarum Hispanicarum. Bd. III: Die iberichen Inschriften aus Spanien (2 vols.). Wiesbaden $=$ MLH III.

UNTERMANN, J., 1993: Intercanvi epistolar en un plom ibèric?, Acta Numismàtica, 21-22-23 = Hom. al Dr. Ll. Villaronga: 93-100.

VIDAL, M.; Magnol, J. P., 1983: Les inscriptions peintes en caractères ibériques de Vieille-Toulouse (Haute-Garonne), Revue Archéologique de Narbonnaise, XVI: 1-28.

Villaronga, Ll., 1967: Las monedas de Arse-Saguntum. Barcelona.

VIllaRONGA, Ll., 1978: Las monedas ibéricas de Ilerda. Barcelona.

Villaronga, Ll., 1979: Numismática antigua de Hispania. Barcelona.

Villaronga, Ll., 1994: Corpus Nummum Hispaniae ante Augusti Aetatem. Madrid. 